\title{
Evaluation of High Density Lipoprotein Cholesterol as a Predictor of Diabetic Nephropathy in Type 1 Diabetic Patients
}

Francis Mugeni Wanyama*, Christine Sekadde Kigondu, Mburu DN, Ngugi NN and Nathan Kiboi

Human Pathology, University of Nairobi, Ngong Road, KNH Complex, Nairobi, Kenya

\begin{abstract}
Background: Diabetic nephropathy is a deadly micro vascular complication of diabetes characterized by albuminuria which manifests mainly 5 years from onset of type 1 diabetes. Currently, the gold standard for its prediction and diagnosis is the demonstration of micro albuminuria, but its predictive power has limitations.

Objective: This study evaluated the higher density lipoprotein cholesterol (HDL-C) levels as a predictor of diabetic nephropathy among type 1 diabetic patients' to provide an alternative to urinary albumin-creatinine ratio (UACR) measurement.

Subjects and methods: A descriptive cross-sectional study of 89 type 1 diabetic patients' from age 13-48 years, attending Kenyatta National Hospital's diabetic clinic were enrolled. A questionnaire was administered to capture the subjects' demographic characteristics. Measured parameters included blood pressure, body mass index, urine albumincreatinine ratio, estimated glomerular filtration rate (eGFR), total and high density lipoprotein cholesterol.

Results: Subjects who had albuminuria and low levels of high density lipoprotein-cholesterol had significantly higher diabetes duration and blood pressure $(p<0.05)$. Single marital status was a significant confounder for albuminuria. Analysis of the subjects at different states of high density lipoprotein cholesterol levels and urine albumin-creatinine ratios showed no significant difference with regard to their gender, literacy level, family history of kidney disease, age, body mass index, estimated glomerular filtration rate and total cholesterol $(P>0.05)$. A significant inverse correlation was found between high density lipoprotein cholesterol and urine albumin-creatinine ratio of the subjects $(r=-0.394$; $p=0.001)$, while correlation between high density lipoprotein cholesterol and estimated glomerular filtration rate was not significant $(r=0.029 ; p=0.098)$.
\end{abstract}

Conclusion: High density lipoprotein cholesterol levels accords a significant predictive value of diabetic nephropathy onset due to its good correlation with urine albumin-creatinine ratio.

Keywords: Diabetic nephropathy; Urine albumin-creatinine ratio; High density lipoprotein-cholesterol; Estimated glomerular filtration rate

\section{Introduction}

Diabetic nephropathy (DN) is the most common complication of diabetes and a leading cause of end stage renal disease (ESRD) in type 1 diabetic patients [1]. The diseases accounts for a significant number of morbidity and mortalities among the diabetics as well as exerting huge social and economic burden on the overall cost of the healthcare system through large numbers of hospital admissions and need for specialized medical care. Diabetic nephropathy classically refers to a set of structural and functional kidney abnormalities in patients with diabetes leading to increased protein excretion in urine $[1,2]$. The main risk factors associated with DN includes uncontrolled hyperglycemia, dyslipidemia, hypertension, and overweight amongst others $[1,3,4]$.

The condition is clinically characterized by increasing rates of urinary albumin excretion whereby the affected slips from normoalbuminuria (UACR $\leq 29 \mathrm{mg} / \mathrm{g}$ ), to micro albuminuria (UACR 30-299 mg/g) also referred to as incipient nephropathy, then progresses to macro albuminuria (UACR $\geq 300 \mathrm{mg} / \mathrm{g}$ ) also called overt nephropathy and eventually to ESRD $[5,6]$. Demonstration of micro albuminuria in diabetic patients is currently the gold standard for detection and prediction of DN. However, its predictive power is limited whereby a decline in the renal function of patients with diabetes is not always accompanied by micro albuminuria and in other cases micro albuminuria might be noted in absence of renal impairment [7-9]. This study therefore, aimed to evaluate whether measurement of HDL-C levels can significantly add predictive value and be a more beneficial alternative marker to UACR in early prediction of DN development among type 1 diabetic patients.

\section{Materials and Methods}

Eighty nine type 1 diabetic patients attending the diabetic clinic at Kenyatta National Hospital and meeting the inclusion criteria were recruited during routine health status examination upon obtaining informed written consent. Approval to carry out the study was sought and granted by the Kenyatta National Hospital/University of Nairobi Research and Ethics Committee.

A standard questionnaire was administered to ascertain age, gender, marital status, education level, family history of kidney disease and the diabetes duration of the subjects. The blood pressure was taken using a sphygmomanometer (Omron healthcare Europe B.V) in supine position. Two readings of blood pressure were made from each participant in space of five minutes and the average recorded. Patients were categorized as hypertensive with sBP above $130 \mathrm{mmHg}$ or with

*Corresponding author: Francis Mugeni Wanyama, Human Pathology, University of Nairobi, Ngong Road, KNH Complex, Nairobi, Nairobi 00202, Kenya, Tel: 254723260351; E-mail: frankmugeni2004@yahoo.co.uk

Received April 28, 2016; Accepted May 16, 2016; Published May 23, 2016

Citation: Wanyama FM, Kigondu CS, Mburu DN, Ngugi NN, Kiboi N (2016) Evaluation of High Density Lipoprotein Cholesterol as a Predictor of Diabetic Nephropathy in Type 1 Diabetic Patients. Clin Med Biochem Open Access 2: 117 doi:10.4172/2471-2663.1000117

Copyright: @ 2016 Wanyama FM, et al. This is an open-access article distributed under the terms of the Creative Commons Attribution License, which permits unrestricted use, distribution, and reproduction in any medium, provided the original author and source are credited. 
$\mathrm{dBP}$ above $85 \mathrm{mmHg}[1,5]$. The height and weight of the subjects was measured using balance beam scale with height road (Seca 700 medical scale; United Kingdom). Body mass index (BMI) was calculated as the weight in kilograms divided by height of the patient in meters squared $\left(\mathrm{kg} / \mathrm{m}^{2}\right), B M I<25 \mathrm{~kg} / \mathrm{m}^{2}$ was considered to be normal weight while levels $>25.1$ were considered as overweight [10].

Spot urine and venous blood samples were collected from each patient for analysis of various biochemical profiles. Urine albumincreatinine ratio (UACR) was determined by the Clinitek $50^{\circ}$ urine chemistry analyser (Bayer healthcare LLC, USA), while serum creatinine, total and high density lipoprotein cholesterol (TC and HDL-C) levels of the subjects were analyzed using Selectra chemistry analyser (Elitech group, clinical systems, Netherlands). Creatinine values were later used for online computation of eGFR levels using the Modification of Diet in Renal Diseases (MDRD) formula for adult subjects ( $\geq 18$ years), available at http://www.nkdep.nih.gov/ professionals/gfr-calculator/org-con.htm, and Counahan-Barratt method for under age subjects ( $<18$ years), using the Steven Fadem calculator available online at www.nephron.com [11-13].

\section{Statistical Analysis}

Data analysis was done using IBM Statistical package for social scientists (SPSS) version 20.0. Continuous variables were expressed as the mean and standard deviation while categorical variables were presented as percentage. Chi squared test (Pearson $\mathrm{X}^{2}$, likelihood ratio and Fishers Exact Test) were used to analyze categorical variables of states of UACR and HDL-C against the confounding variables. While unpaired $t$ test, one way ANOVA and Pearson's correlation analysis were used to analyze between groups continuous variables. Statistical significance was denoted at $\mathrm{p}<0.05$.

\section{Results}

\section{Patients' characteristics and associations}

A descriptive summary of demographic, clinical and biochemical characteristics of the subjects in different states of UACR, HDL-C and eGFR levels are presented in Tables 1 and 2. Out of the 89 subjects, 37 (42\%) were males while $52(58 \%)$ were females. The married subjects accounted for $37 \%$ while, $63 \%$ were single. Evaluation of the literacy standards of the subjects according to the level of education attained showed that 25 (28\%), 40 (45\%) and 24 (27\%) had attained primary, secondary and tertiary education, respectively. Only $6(7 \%)$ of the subjects had history of kidney disease in their families. The average age of the subjects' was $25 \pm 8.9$ years and the mean duration of diabetes for the subjects was $8.6 \pm 4.7$ years. Subjects had an average BMI of $22.5 \pm$ $3.6 \mathrm{kgm}^{2}$, while the average blood pressure for systole and diastole were $120.7 \pm 19.9 \mathrm{mmHg}$ and $76.2 \pm 11 \mathrm{mmHg}$, respectively. Mean values for biochemical parameters were $4.40 \pm 1.11 \mathrm{mmol} / \mathrm{L}, 1.33 \pm 0.38 \mathrm{mmol} / \mathrm{L}$, $115.3 \pm 38.6 \mathrm{~mL} / \mathrm{min} / 1.73 \mathrm{~m}^{2}$ for TC, HDL-C and eGFR, respectively.

Of the 89 subjects, 49 (55\%) had normoalbuminuria, while 40 (45\%) presented albuminuria of which $88 \%$ were microalbuminuric and $12 \%$ with macroalbuminuria. A statistically significant difference was found between UACR states of the subjects with respect to their marital status, diabetes duration, blood pressure and HDL-C levels $(\mathrm{p}<0.05)$. On the other hand, no significant difference was found on the account of gender, literacy level, family history of kidney disease, age, BMI, eGFR and total cholesterol.

Table 2 shows that $17 \%$ of the subjects had normal levels of HDL-C, while $67 \%$ and $16 \%$ had borderline low and low levels of HDL-C, respectively. A statistically significant difference was found between HDL-C states of the subject with respect to diabetes duration, blood pressure and UACR levels $(\mathrm{p}<0.05)$, while no significant difference was found with regard to gender, educational, level, family history of kidney disease, age, BMI, eGFR and total cholesterol.

\section{Distribution of HDL-C values of subjects in UACR states}

Subjects were distributed in UACR states according to their HDL-C values (Figure 1). Of the 49 subjects with normoalbuminuria, $14(29 \%), 33(67 \%)$ and 2 (4\%), had normal, borderline low and low HDL-C values, respectively. On the other hand, the albuminuric group with 40 subjects, only one (3\%) patient had normal HDL-C value, while 27 (67\%) and 12 (30\%) had borderline low and low HDL-C values. The mean HDL-C level for albuminuric subjects was significantly lower than for the normoalbuminuric group $(1.19 \mathrm{mmol} / \mathrm{L} v s 1.47 \mathrm{mmol} / \mathrm{L}$; $\mathrm{p}=0.001$ ).

\begin{tabular}{|c|c|c|c|c|}
\hline & \multirow[b]{2}{*}{ Total } & \multicolumn{2}{|c|}{$\begin{array}{l}\text { Urine albumin creatinine } \\
\text { ratio states }\end{array}$} & \multirow{2}{*}{$\begin{array}{c}P \\
\text { value }\end{array}$} \\
\hline & & $\begin{array}{c}\text { Normo- } \\
\text { Albuminuria }\end{array}$ & Albuminuria & \\
\hline $\mathrm{n}$ & 89 & $49(55)$ & $\begin{array}{c}40(45) \\
\text { (Microalb 35) } \\
\text { (Macroalb 5) }\end{array}$ & \\
\hline Gender (\%) & & & & 0.786 \\
\hline Male & $37(42)$ & $21(43)$ & $16(40)$ & \\
\hline Female & $52(58)$ & $28(57)$ & $24(60)$ & \\
\hline Marital status (\%) & & & & $0.033^{*}$ \\
\hline Single & $56(63)$ & $26(53)$ & $30(75)$ & \\
\hline Married & $33(37)$ & $23(47)$ & $10(25)$ & \\
\hline Education level (\%) & & & & 0.426 \\
\hline Primary & $25(28)$ & $15(31)$ & $10(25)$ & \\
\hline Secondary & $40(45)$ & $19(38)$ & $21(52)$ & \\
\hline Tertiary & $24(27)$ & $15(31)$ & $9(23)$ & \\
\hline $\begin{array}{l}\text { Family history of kidney } \\
\text { disease } \%\end{array}$ & & & & 0.687 \\
\hline With & $6(7)$ & $4(8)$ & $2(5)$ & \\
\hline Without & $83(93)$ & $45(92)$ & $38(95)$ & \\
\hline Age (years) & $25 \pm 8.9$ & $25 \pm 8.2$ & $26 \pm 9.7$ & 0.395 \\
\hline Diabetes duration (years) & $8.6 \pm 4.7$ & $6.8 \pm 2.3$ & $10.8 \pm 6.0$ & $0.000^{*}$ \\
\hline BMI $\left(\mathrm{Kg} / \mathrm{m}^{2}\right)$ & $22.5 \pm 3.6$ & $22.7 \pm 4.1$ & $22.3 \pm 2.8$ & 0.611 \\
\hline \multicolumn{5}{|l|}{ Blood pressure $(\mathrm{mmHg})$} \\
\hline Systolic & $120.7 \pm 19.9$ & $113.9 \pm 16.0$ & $128.7 \pm 21.3$ & $0.000^{*}$ \\
\hline Diastolic & $76.2 \pm 11$ & $72.5 \pm 11.8$ & $80.1 \pm 9.4$ & $0.001^{*}$ \\
\hline $\mathrm{HDL}-\mathrm{C}(\mathrm{mmol} / \mathrm{L})$ & $1.33 \pm 0.38$ & $1.47 \pm 0.41$ & $1.19 \pm 0.27$ & $0.001^{*}$ \\
\hline Total cholesterol $(\mathrm{mmol} / \mathrm{l})$ & $4.40 \pm 1.11$ & $4.23 \pm 0.98$ & $4.58 \pm 1.24$ & 0.155 \\
\hline eGFR $\left(\mathrm{ml} / \mathrm{min} / 1.73 \mathrm{~m}^{2}\right)$ & $115.3 \pm 38.6$ & $121.9 \pm 34.9$ & $105.7 \pm 41.9$ & 0.054 \\
\hline
\end{tabular}

Data are percentage, mean $\pm \mathrm{SD}$; hypertensive (systolic and diastolic blood pressure $>130 / 85 \mathrm{mmHg})$; overweight $\left(\mathrm{BMl}>25.1 \mathrm{~km} / \mathrm{m}^{2} ;\right.$ normoalbuminuria (UACR, $\leq 29 \mathrm{mg} / \mathrm{g}$ ), albuminuria includes patients with microalbuminuria (UACR, $30-299 \mathrm{mg} / \mathrm{g}$ ) and macroalbuminuria (UACR, $\geq 300 \mathrm{mg} / \mathrm{g}$ ); Dyslipidemia (total cholesterol $\geq 6.1 \mathrm{mmol} / \mathrm{l}, \mathrm{HDL}-\mathrm{C} \leq 1.04$ ), reduced renal filtration (eGFR $\leq 90 \mathrm{ml} /$ $\min / 1.73 \mathrm{~m}^{2}$ ) p values are based on chi-squared test for proportions and one way Anova, $t$ test for means. Statistical significance was denoted at $p<0.05\left[{ }^{*}\right]$. Values in parenthesis are percentages.

Table 1: Characterization of subjects' data within levels of UACR states. 

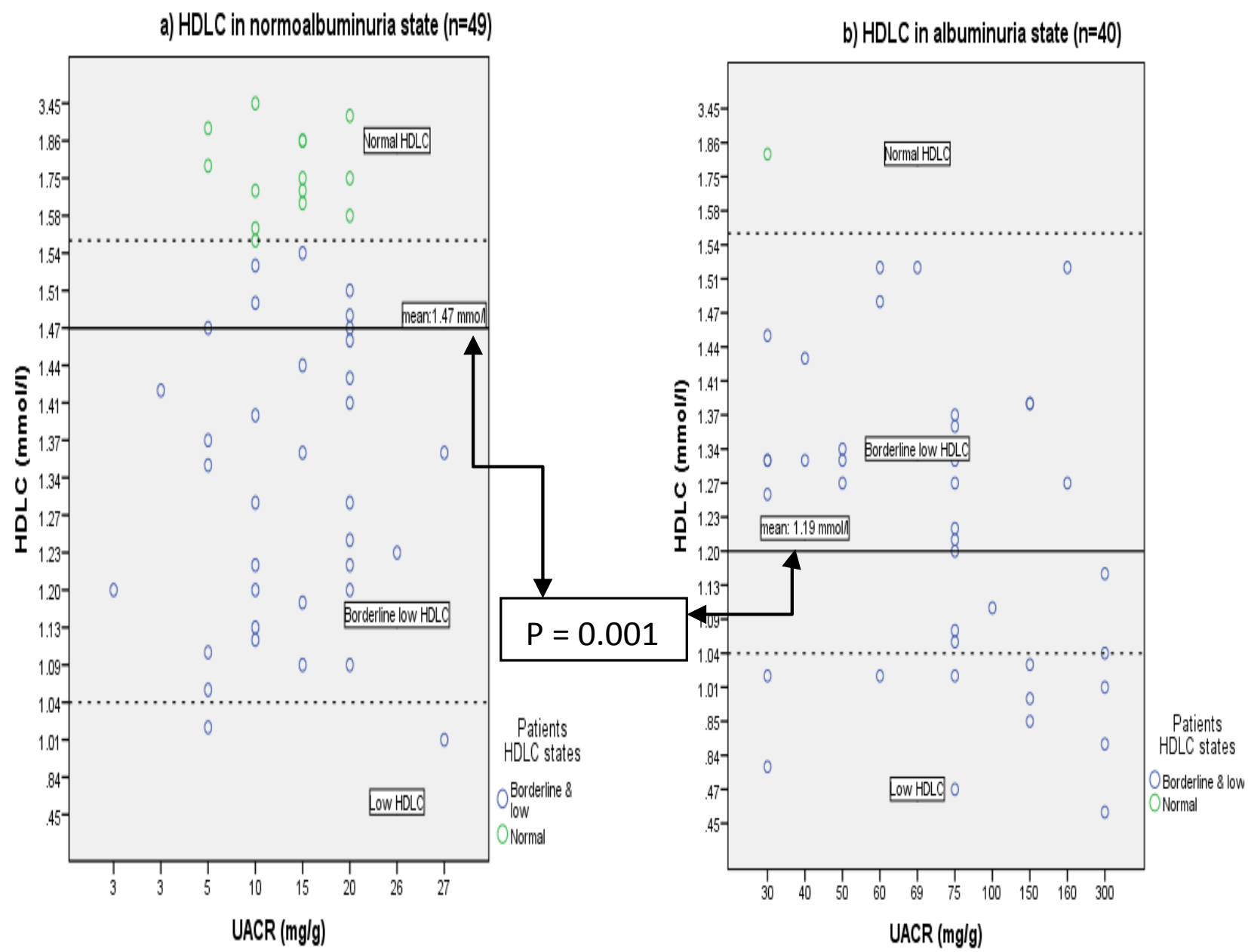

Continuous line mean level of HDL-C for all the subjects in UACR states; Broken line Categorizations of the subjects based on their levels of HDL-C states

Figure 1: Distribution of HDL-C values in UACR states.

\section{Correlation of HDL-C with UACR and eGFR values}

There was a significant inverse correlation between HDL-C and UACR values of the subjects $(r=-0.394 ; \mathrm{P}=0.001)$ whereby, when HDL-C values decreased, there was a corresponding increase in the UACR values. However, a poor non-significant correlation was found between HDL-C and eGFR values ( $r=0.029 ; \mathrm{P}=0.098)$.

\section{Discussion}

The current study sought to evaluate the predictive power of HDL-C levels in predicting DN by correlating with UACR values and also by evaluating the subjects' demographic and clinical characteristics with respect to UACR and HDL-C states.

Evaluation of UACR states of the subjects found that, patients with norm albuminuria and albuminuria differed significantly on the basis of their marital status, whereby the later was more prevalent in subjects with single marital status. Hence marital status is a significant confounding variable for albuminuria, which needs to be looked into while designing a model for the home based care for the diabetics. A finding which is in agreement with August et al. who observed that within the social support network, the spouse is the most important source of support on matters relating to health management especially dietary and treatment adherence [14]. Similarly, significant difference was found with regard to duration of diabetes, HDL-C levels, and blood pressure (systolic and diastolic). Albuminuric subjects, had higher diabetes duration, low HDL-C levels and higher systolic and diastolic blood pressure which is in keeping with the findings from previous studies $[1,4,5,9]$. This implied that they are high risk factors likely to be associated with the development of diabetic nephropathy. However, analysis of the subjects' gender, family history of kidney disease, age, BMI, total cholesterol and eGFR levels found no significant difference between normoalbuminuric and albuminuric subjects. This suggests that they may be low risk factors likely or unlikely to be associated with development of DN. This observation was in accord with the findings of Afkhami-Ardekani et al., Ahmedani et al. and Tabaei et al. [2,4,9,15]. The level of education attained by the subjects was also found not to be a confounding variable for albuminuria in this study. It was noted that subjects with albuminuria were generally older, had longer duration of diabetes with higher systolic and diastolic blood pressure as well as reduced levels of HDL-C and eGFR.

Analysis of the subjects' characteristics at the three states of HDL-C levels - normal, borderline and low - showed significant differences between the three states with regard to the duration of diabetes, blood pressure (systole and diastole) and UACR levels. This observation 


\begin{tabular}{|c|c|c|c|c|}
\hline & \multicolumn{3}{|c|}{$\begin{array}{l}\text { High density lipoprotein cholesterol } \\
\text { states }\end{array}$} & \multirow{2}{*}{$P$ value } \\
\hline & Normal & $\begin{array}{l}\text { Borderline } \\
\text { low }\end{array}$ & Low & \\
\hline$n=89$ & $15(17)$ & $60(67)$ & $14(16)$ & \\
\hline Gender (\%) & & & & 0.130 \\
\hline Male & $5(33)$ & $29(48)$ & $3(21)$ & \\
\hline Female & $10(67)$ & $31(52)$ & $11(79)$ & \\
\hline Marital status (\%) & & & & 0.393 \\
\hline Single & $9(60)$ & $36(60)$ & $11(79)$ & \\
\hline Married & $6(40)$ & $24(40)$ & $3(21)$ & \\
\hline Education level (\%) & & & & 0.155 \\
\hline Primary & $3(20)$ & $19(32)$ & $3(22)$ & \\
\hline Secondary & $7(47)$ & $23(38)$ & $10(71)$ & \\
\hline Tertiary & $5(33)$ & $18(30)$ & $1(7)$ & \\
\hline $\begin{array}{l}\text { Family history of kidney } \\
\text { disease (\%) }\end{array}$ & & & & 0.336 \\
\hline With & $1(7)$ & $5(8)$ & $0(0)$ & \\
\hline Without & $14(93)$ & $55(92)$ & $14(100)$ & \\
\hline Age (years) & $26 \pm 6.6$ & $25 \pm 9.1$ & $28 \pm 10.4$ & 0.517 \\
\hline Diabetes duration (years) & $7 \pm 2.1$ & $8 \pm 4.1$ & $12 \pm 7.3$ & $0.005^{*}$ \\
\hline Body mass index $\left(\mathrm{Kg} / \mathrm{m}^{2}\right)$ & $22.9 \pm 3.3$ & $22.4 \pm 3.9$ & $22.3 \pm 2.8$ & 0.903 \\
\hline \multicolumn{5}{|l|}{ Blood pressure $(\mathrm{mmHg})$} \\
\hline Systolic & $\begin{array}{c}113.9 \pm \\
22.3\end{array}$ & $119.4 \pm 15.7$ & $\begin{array}{c}132.7 \pm \\
28.5\end{array}$ & $0.027^{*}$ \\
\hline Diastolic & $69 \pm 15.7$ & $77.12 \pm 10.3$ & $77.9 \pm 8.1$ & $0.035^{*}$ \\
\hline UACR $(\mathrm{mg} / \mathrm{g})$ & $14.3 \pm 6.5$ & $44.9 \pm 52.1$ & $\begin{array}{c}139.4 \pm \\
115.3\end{array}$ & $<0.001^{*}$ \\
\hline Total cholesterol (mmol/L) & $4.38 \pm 0.84$ & $4.47 \pm 1.23$ & $4.03 \pm 0.77$ & 0.412 \\
\hline eGFR $\left(\mathrm{ml} / \mathrm{min} / 1.73 \mathrm{~m}^{2}\right)$ & $\begin{array}{c}109.6 \pm \\
30.8\end{array}$ & $120.2 \pm 41.1$ & $\begin{array}{c}95.91 \pm \\
31.9\end{array}$ & 0.093 \\
\hline
\end{tabular}

Data are percentage, mean $\pm \mathrm{SD}$; hypertensive (systolic and diastolic blood pressure $>130 / 85 \mathrm{mmHg}$ ); overweight $\left(\mathrm{BMl}>25.1 \mathrm{~km} / \mathrm{m}^{2}\right.$; normoalbuminuria (UACR, $\leq 29 \mathrm{mg} / \mathrm{g}$ ), albuminuria includes patients with microalbuminuria (UACR, $30-299 \mathrm{mg} / \mathrm{g}$ ) and macroalbuminuria (UACR, $\geq 300 \mathrm{mg} / \mathrm{g}$ ); Dyslipidemia (tota cholesterol $\geq 6.1 \mathrm{mmol} / \mathrm{L}, \mathrm{HDL}-\mathrm{C} \leq 1.04$ ), reduced renal filtration (eGFR $\leq 90 \mathrm{ml} /$ $\min / 1.73 \mathrm{~m}^{2}$ ) p values are based on chi-squared test for proportions and one way Anova, $\mathrm{t}$ test for means. Statistical significance was denoted at $p<0.05\left[{ }^{*}\right]$. Values in parenthesis are percentages.

Table 2: Characterization of subjects' data within levels of HDL-C states.

suggests that they are significant confounding variables for reduced HDL-C levels, a finding which is in concordance with previous studies $[5,16,17]$. However, no significant difference was found with respect to gender, marital status, education level, family history of kidney disease, age, BMI, total cholesterol and eGFR levels, hence this variables are not significant confounders for the low HDL-C levels in the subjects, an observation which is in agreement with findings from past studies $[2,10,18]$. Just like for the subjects with albuminuria, patients with low HDL-C levels were generally, older, had longer duration of diabetes, and had higher systolic and diastolic blood pressure as well as higher UACR and reduced eGFR levels.

A bivariate analysis of UACR and HDL-C values of the subjects showed a significant inverse correlation $(\mathrm{r}=-0.394 ; \mathrm{p}<0.05)$, which is similar to findings of past studies $[9,19]$. This means that the
HDL-C levels may be used in place of UACR levels for the purpose of predicting $\mathrm{DN}$ or still, both may be measured to improve on predictive precision and efficiency. On the other hand, HDL-C values did not significantly associate with eGFR values $(r=0.029$; $p>0.05)$, which is in accord with findings of some past studies, which observed that only a subset of patients with micro albuminuria exhibits rapid decline in eGFR, meaning that some patients with diabetic nephropathy may have normal eGFR levels $[11,18]$. Also, longstanding type I diabetics develop glomerular lesions which reduces the kidney function affecting the regulation of HDL-C metabolism and also causing persistent micro albuminuria even if treatment is administered. Thus in such patients, micro albuminuria may be a marker rather than a predictor of renal structural changes [18]. The Danish group study which followed up 301 type 1 diabetes patients for 7 years confirmed the power of serum cholesterol in predicting the progression of DN [20].

\section{Conclusions}

Determination of HDL-C levels accords significant predictive value of development of DN among type 1 diabetic mellitus patients of four years into diagnosis as shown by the good correlation with UACR levels; hence it may be used in place of UACR to compensate for its specificity concerns. However, for optimal prediction of DN onset, both should be concurrently determined during the patients' routine health status check, to improve on predictive precision and efficiency. Longer duration of diabetes and high blood pressures were associated with albuminuria and low HDL-C levels hence they are high risk factors for the development of diabetic nephropathy. Therefore, type 1 diabetic patients' of $4 \frac{1}{2}$ years into diagnosis should have their blood pressure measured routinely to enable early detection and intervention in cases of high blood pressure.

\section{Acknowledgements}

It is with pleasure and deep sense of indebtness that I acknowledge the invaluable help of the institutions and individuals that contributed immensely to the fulfillment of the mandate of this study; the management and staff of the Kenyatta National Hospital's diabetic clinic and the University of Nairobi's thematic unit of Clinical Chemistry's laboratory. Mrs. Anne Alindah for data processing and typing of the manuscript.

\section{References}

1. Afkhami-Ardekani M, Modarresi M, Amirchaghmaghi E (2008) Prevalence of microalbuminuria and its risk factors in type 2 diabetic patients. Indian $\mathrm{J}$ Nephrol 18: 112-117

2. Ayodele OE, Alebiosu CO, Salako BL (2004) Diabetic nephropathy--a review of the natural history, burden, risk factors and treatment. J Natl Med Assoc 96: 1445-1454.

3. Vujicic B, Tuvic T, Crncevic-orlic G, Racki S (2012) Pathophysiology and complications of diabetes mellitus. In tech 3: 71-89.

4. Celepkolu T, Mehmet HT, Celik SB, Pakize GB, Can H, et al. (2014) The evaluation of nephropathy risk factors in type 2 diabetes. Acta medica Mediterranean 30: 221-226.

5. Ahmedani MY, Hydrie MZ, lqbal A, Gul A, Mirza WB, et al. (2005) Prevalence of microalbuminuria in type 2 diabetic patients in Karachi: Pakistan: a multi-center study. J Pak Med Assoc 55: 382-386.

6. ADA (2010) Diagnosis and classification of diabetes mellitus: Diabetes Care Journal 33: s62-s69.

7. Matheson A, Willcox MD, Flanagan J, Walsh BJ (2010) Urinary biomarkers involved in type 2 diabetes: a review. Diabetes Metab Res Rev 26: 150-171.

8. Miller WG, Bruns DE, Hortin GL, Sandberg S, Aakre KM, et al. (2009) Current issues in measurement and reporting of urinary albumin excretion. Clin Chem 55: 24-38.

9. Molitch ME, Rupp D, Carnethon M (2006) Higher levels of HDL cholesterol are associated with a decreased likelihood of albuminuria in patients with longstanding type 1 diabetes. Diabetes Care 29: 78-82. 
Citation: Wanyama FM, Kigondu CS, Mburu DN, Ngugi NN, Kiboi N (2016) Evaluation of High Density Lipoprotein Cholesterol as a Predictor of Diabetic Nephropathy in Type 1 Diabetic Patients. Clin Med Biochem Open Access 2: 117. doi:10.4172/2471-2663.1000117

Page 5 of 5

10. Rosenbaum M, Leibel RL, Hirsch J (1997) Obesity. N Engl J Med 337: 396-407.

11. Levey AS, Bosch JP, Lewis VB, Green T, Rogers N et al. (1999) A more accurate method to estimate glomerular filtration rate from serum creatinine: a new prediction equation. Modification of diet in Renal disease study group: Annals of Intern Medicine 130: 461-70.

12. NKF (2007) Kidney disease outcome quality initiative, clinical practice guidelines and clinical practice recommendations for diabetes and chronic kidney disease. American Journal of Kidney Disease 49: 2-9.

13. Counahan R, Chantler C, Ghazali S, Kirkwood B, Rose F, et al. (1976) Estimation of glomerular filtration rate from plasma creatinine concentration in children. Arch Dis Child 51: 875-878.

14. August KJ, Sorkin DH (2010) Marital status and gender differences in managing a chronic illness: the function of health-related social control. Soc Sci Med 71: 1831-1838.

15. Tabaei BP, Kassab AS, llag LL, Zawacki CM, Herman WH (2001) Does microalbuminuria predict diabetic nephropathy? Diabetes Care 24: 1560-1565
16. Agarwal N, Sengar NS, Jain PK, Khare R (2011) Nephropathy in newly diagnosed type 2 diabetics with special stress on the role of hypertension. $J$ Assoc Physicians India 59: 145-147.

17. Morton J, Zoungas S, Li Q, Patel AA, Chalmers J, et al. (2012) Low HDL cholesterol and the risk of diabetic nephropathy and retinopathy: results of the ADVANCE study. Diabetes Care 35: 2201-2206.

18. Wang F, Zheng J, Ye P, Luo L, Bai Y, et al. (2013) Association of highdensity lipoprotein cholesterol with the estimated glomerular filtration rate in a community-based population. PLoS One 8: e79738.

19. Aziz KMA, Al-Qahtzmi (2013) Association between non- HDL and HDL cholesterol with microalbuminuria in patients with Diabetes: Journal of Diabetology: 11: 2011-2014.

20. Appel GB, Radhakrishnan J, Avram MM, DeFronzo RA, Escobar-Jimenez F, et al. (2003) Analysis of metabolic parameters as predictors of risk in the RENAAL study. Diabetes Care 26: 1402-1407.

Citation: Wanyama FM, Kigondu CS, Mburu DN, Ngugi NN, Kiboi N (2016) Evaluation of High Density Lipoprotein Cholesterol as a Predictor of Diabetic Nephropathy in Type 1 Diabetic Patients. Clin Med Biochem Open Access 2 : 117. doi:10.4172/2471-2663.1000117 